\title{
HISTOENDOCRINOLOGICAL CHANGES INDUCED BY STRESS IN THYROID GLAND OF ALBINO RATS
}

\author{
Vandana Tewari ${ }^{1}$, Samarjeet Kaur², R. K. Srivastava ${ }^{3}$
}

${ }_{1}^{1}$ Associate Professor, Department of Anatomy, Rama Medical College, Kanpur, Uttar Pradesh, India.

${ }^{2}$ Assistant Professor, Department of Community Medicine, GSVM Medical College, Kanpur, Uttar Pradesh, India.

3 Professor, Department of Anatomy, Rama Medical College, Kanpur, Uttar Pradesh, India.

\section{BACKGROUND}

ABSTRACT

The separation of Psychology from the premises of Biology is purely artificial, as the human psyche lives in dissoluble union with the body. Bodily changes are brought about by mental stimuli and emotions as effectively as bacteria and toxins.(1) Psychological changes can disturb the function of any organ and bring about somatic manifestations, the neuroendocrine effects of stress are mediated by hypothalamus (May field 1980)(2) as it serves as a transducer that translates higher neural activity into physiological responses, as on thyroid gland, it causes increase in T3 levels, variable changes in T4 levels and brings about significant histological changes.

\section{MATERIALS AND METHODS}

A Non Randomized Controlled Study was done in 60 albino rats, divided into 3 groups of 20 each with ten males and ten females in each group, Histology of thyroid gland was studied after processing and staining with H \&E Stain, Masons and trichome stain, in immobilized rats for different durations, (Immobilization stress was chosen as it is not physically painful to rats and served as both physical and psychological stressor) maximum up to 3 months as control, test and diazepam treated groups, animals were sacrificed and blood for hormonal estimation was collected by decapitation.

Observations- study revealed bigger thyroidal follicles with high cuboidal epithelium, cytoplasm getting basophilic from eosinophilic presence of vacuoles and variable increase in T3 and T4 levels, all in favour of cellular hypertrophy and hyperplasia.

\section{RESULTS}

Significant increase found in escape behaviour and aggressiveness of the animal, histological changes were in favour of hypertrophy and hyperplasia, increase in T3 and T4 levels were observed, diazepam partially antagonized the effect of stress on all the parameters observed.

\section{CONCLUSION}

Immobilisation stress causes hyper activity of thyroid gland in form of follicular hyperplasia and cellular hypertrophy and significant increase in T4 levels, diazepam partially antagonized the effect of stress on all the parameters observed.

\section{KEY WORDS}

Neuroendocrine, Stress, Hypertrophy, Hyperplasia.

HOW TO CITE THIS ARTICLE: Tewari V, Kaur S, Srivastava RK. Histoendocrinological changes induced by stress in thyroid gland of albino rats. J. Evolution Med. Dent. Sci. 2019;8(06):377-380, DOI: 10.14260/jemds/2019/83

\section{BACKGROUND}

It has been proved through countless studies that our mental attitude has powerful influence on our physical health. The body and the mind are not two separate entities- all kinds of mental or physical stressors simultaneously influence the body and the mind and leads to psychosomatic disease. Mental stimuli and emotions can cause bodily change as effectively as bacteria and toxins. The psychological change may disturb the function of any organ of the body with somatic manifestation. In the present study it was intended to study the effect of immobilization stress which acts as physical as well as psychological stressor, on the histomorphology of thyroid gland and thyroid hormones (T3

'Financial or Other Competing Interest': None.

Submission 22-12-2018, Peer Review 30-01-2019,

Acceptance 04-02-2019, Published 11-02-2019.

Corresponding Author:

Dr. Samarjeet Kaur,

Assistant Professor,

Department of Community Medicine,

GSVM Medical College,

Kanpur, Uttar Pradesh, India.

E-mail: drsamarjeetkaur@gmail.com

DOI: $10.14260 /$ jemds $/ 2019 / 83$ and T4). Effect of stress over thyroid gland is mediated by hypothalamo hypophyseal axis.

\section{Hypothalamus}

Has been called the 'Head Ganglion of Autonomic Nervous System' as the autonomic responses triggered in hypothalamus are part of complex phenomenon such as rage and emotions which occur as a result to any sort of stress on human body, actually the neural basis of instinctual behaviour and emotions lie as in the limbic system.(3) Hypothalamus and limbic system are intimately connected to each other and are concerned with feeding sexual behaviour, emotions rage fear and motivation,(4) Hypothalamus secretes thyrotropin releasing hormone which in turn acts over anterior pituitary to cause secretion of thyrotropin which act over thyroid gland to secrete thyroid hormones.

Morphofunctional changes in thyroid glands seen by Krasnoperov et al 1993. He reported that restraint stress cause hyperactivity of thyroid gland with increase in T3 levels and variable changes in $\mathrm{T} 4$ levels.(5) 


\section{MATERIALS \& METHODS}

The Non-Randomized Controlled Study was carried out on 60 albino rats divided into three groups of twenty each with ten males and ten females in each group. Purposive sampling was done. Further subgrouping was done, and each group was divided into five group of four rats, each having two males and two females in each group. The three groups of rats were labelled as Group A, Group B. and Group C.

The rats of group A were taken as control. They were housed in large wire cage and were free to move.

The rats of group B were immobilized in small Transparent plastic jars with five holes, for four hours, daily, for 3 months the rats of group B were immobilized in similar manner and were given injections of diazepam $0.15 \mathrm{mg} / 100$ gm of body weight during the period of stress Diazepam was used to eliminate the stress. all the animals were sacrificed over the time span of three months altogether ranging from first, third, seventh and fifteenth day of starting experiment and at the end of three months blood was collected directly from the heart for hormonal estimation. Thyroid glands were identified and dissected out. After thorough washing of tissues with normal saline, they were kept into $10 \%$ formaldehyde Tissues were processed for paraffin section and stained with Haematoxylin eosin, Masons trichrome stains.

\section{Statistical Analysis}

The data was compiled and analysed using SPSS 23.0. Continuous variables were analysed using mean and standard deviation, comparison of means in different groups was done using one-way ANOVA and post hoc Tukey Test. $\mathrm{P}$ value less than 0.05 was considered significant.

\section{RESULTS}

\section{Control Group}

Thyroid gland of albino rat was surrounded by a thin capsule made up of the connective tissue, sparsely distributed collagenous fibres were seen in inter follicular, along with blood vessels. Thyroid. follicles were almost uniformly distributed. The peripheral follicles were slightly larger than the centrally located ones and were filled with. Homogenous eosinophilic colloid, follicular cells appeared to be low cuboidal or even flattened with centrally placed mildly vesicular nuclei.

\section{Stress Group}

We observed that rats of stress group were inactive as compared to the control group and diazepam treated rates. They showed significant increase in escape behaviour and were very much aggressive at the time they were attended for meals etc.(6) Stress males showed marked increase in body weight paralleled by an increase in food consumption.

Histological study showed that stress causes definite changes in thyroid gland.

There was evidence of thyroid hyperactivity, seen maximum in the stress group. Histological study showed that there was cellular hypertrophy and follicular hyperplasia. Peripheral follicles were smaller than the central ones colloid was filled in the follicles in the control and diazepam group whereas stress group showed multiple small empty follicles or follicles with very few amount of colloid. Section s of thyroid gland from the group sacrificed on $1^{\text {st }}, 3^{\text {rd }}$ and $7^{\text {th }}$ day showed empty follicles whereas the group sacrificed on $15^{\text {th }}$ day and three months showed thyroid gland filled with reasonable amount of colloid.

Epithelium of the follicles was low cuboidal or flattened in the control and diazepam group whereas it was high cuboidal to tall columnar with basal euchromatic nuclei in stress group. Vacuoles were also seen at the periphery of colloid more in female. In groups sacrificed at three months large pericolloidal spaces were found in the follicles. ${ }^{7}$ )

Cytoplasm was eosinophilic in control and diazepam group whereas it became light basophilic to deep basophilic in the stress group. Increased Mitotic activity and granules were seen the follicular cells in stress group 4 level was significantly increased ${ }^{(8)}(\mathrm{P}<0.01)$ in the blood samples taken from rats sacrificed on the $1^{\text {st }}, 3^{\text {rd }}$ and $7^{\text {th }}$ day however the $\mathrm{T} 4$ level was not significantly raised at the end of 3 months $(\mathrm{P}<$ 0.01). Diazepam treatment significantly $(\mathrm{P}<0.01)$ antagonized the effect of stress on $\mathrm{T} 4$ level.

\section{Effect of Stress on T4 Levels}

\begin{tabular}{|c|c|c|c|c|c|}
\hline \multirow[t]{2}{*}{ Group } & \multicolumn{4}{|c|}{ DAYS } & \multirow[b]{2}{*}{ 3Month } \\
\hline & $1^{\text {st }}$ day & $3^{\text {rd }}$ day & $7^{\text {th }}$ day & $15^{\text {th }}$ day & \\
\hline Control & $6.56( \pm 2.31)$ & $5.89( \pm 1.26)$ & $5.25( \pm 1.10)$ & $4.72( \pm 0.96)$ & $7.6( \pm 1.34)$ \\
\hline Stress Grp & $7.78( \pm 2.52)$ & $7.64( \pm 1.87)$ & $6.41( \pm 1.27)$ & $6.25( \pm 1.83)$ & $24.6( \pm 1.68)$ \\
\hline Stress with & 7.63. $( \pm 1.89)$ & 7.23. $( \pm 2.16)$ & $5.48( \pm 1.01)$ & 6.47. $( \pm 1.73)$ & $8.9( \pm 1.57)$ \\
\hline Diazepam & & & & & \\
\hline Group & & & & & \\
\hline & Table 1. Av & erage Serum 1 & T4 Level in Ma & $\mathrm{RATS}(\mathrm{ng} / \mathrm{ml})$ & \\
\hline
\end{tabular}

It is apparent from table-I that maximum increase in T4 level was seen at the end of three months however the increase in the hormonal level started from the very first day of starting experiment after giving immobilization stress for 5 hours. T4 level kept on increasing until the seventh day of immobilization stress but observed the decline on the fifteenth day.

However, the level was found very high at the end of three months. These finding very well correlate with the histological findings. Thus, immobilization stress causes increase in in T4 level and Diazepam alleviated the stress significantly. 


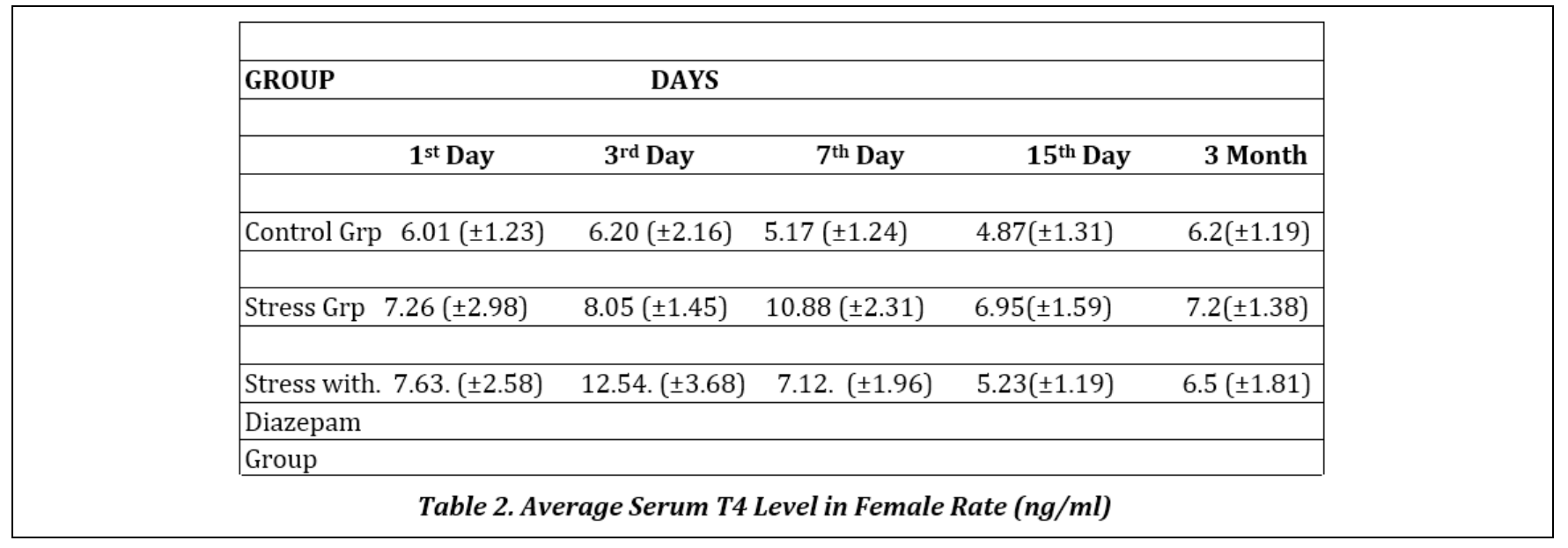

Table-II shows irregular pattern of change in T4 level in female. However, stress did not cause rise in T4 level. But Diazepam still lowered the values of T4 partially in females.

\begin{tabular}{|c|c|c|c|c|}
\hline & Group A & Group B & Group C & p-Value \\
\hline At 3 Months & $7.6 \pm 1.34$ & $24.6 \pm 1.68$ & $8.9 \pm 1.57$ & $<0.001^{*}$ \\
\hline Day 1 & $6.56 \pm 2.31$ & $7.78 \pm 2.52$ & $7.63 \pm 1.89$ & 0.184 \\
\hline Table 3. Comparison of T4 Levels in The Three Groups in \\
Male Rats \\
\hline \multicolumn{4}{|c|}{ *Tukey HSD Post-hoc Test... } \\
Group 1 vs Group 2: $\mathrm{p}=0.0259$ \\
Group 1 vs Group 3: $\mathrm{p}=0.8620$ \\
Group 2 vs Group 3: $\mathrm{p}=0.8001$ \\
\hline
\end{tabular}

Table 3 shows that there was no significant difference of T4 level observed among male rats on day 1. On $3^{\text {rd }}$ month T4 levels between the 3 groups are found to be significantly different $(p<0.001)$. Upon applying Tukey HSD post hoc test significant difference was found between group $A$ and group B.

\begin{tabular}{|c|c|c|c|c|}
\hline & Group A & Group B & Group C & p-Value \\
\hline Day 1 & $6.01 \pm 1.23$ & $7.26 \pm 2.98$ & $7.63 \pm 2.58$ & 0.088 \\
\hline At 3 Months & $6.2 \pm 1.19$ & $7.2 \pm 1.38$ & $6.5 \pm 1.81$ & 0.1 \\
\hline Table 4. Comparison of T4 Levels in The Three Groups in \\
Female Rats \\
\hline
\end{tabular}

Table 4 shows no significant difference of T4 levels in 3 groups among female rats was seen on Day 1 . On the 3 rd month also there was no significant difference in T4 levels in 3 groups.
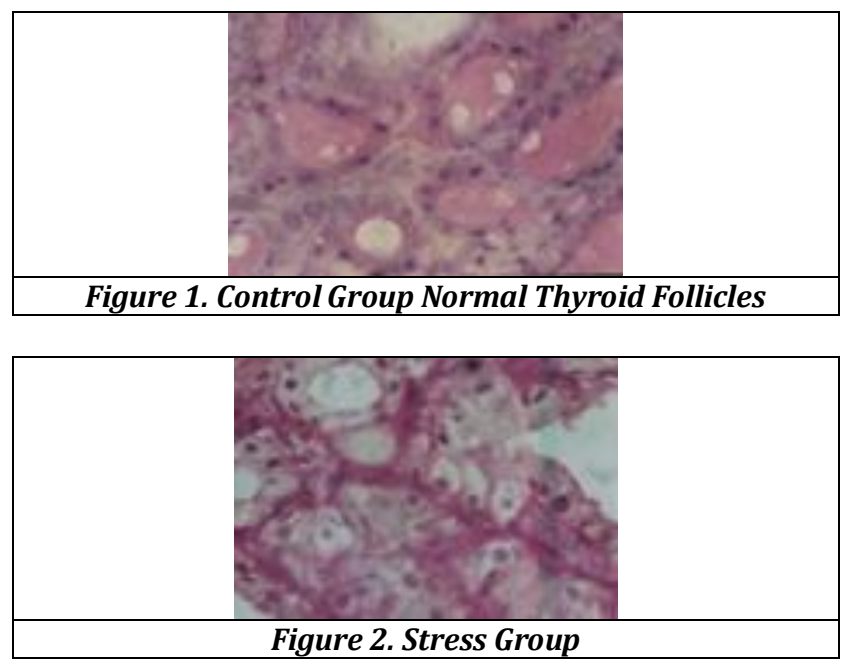
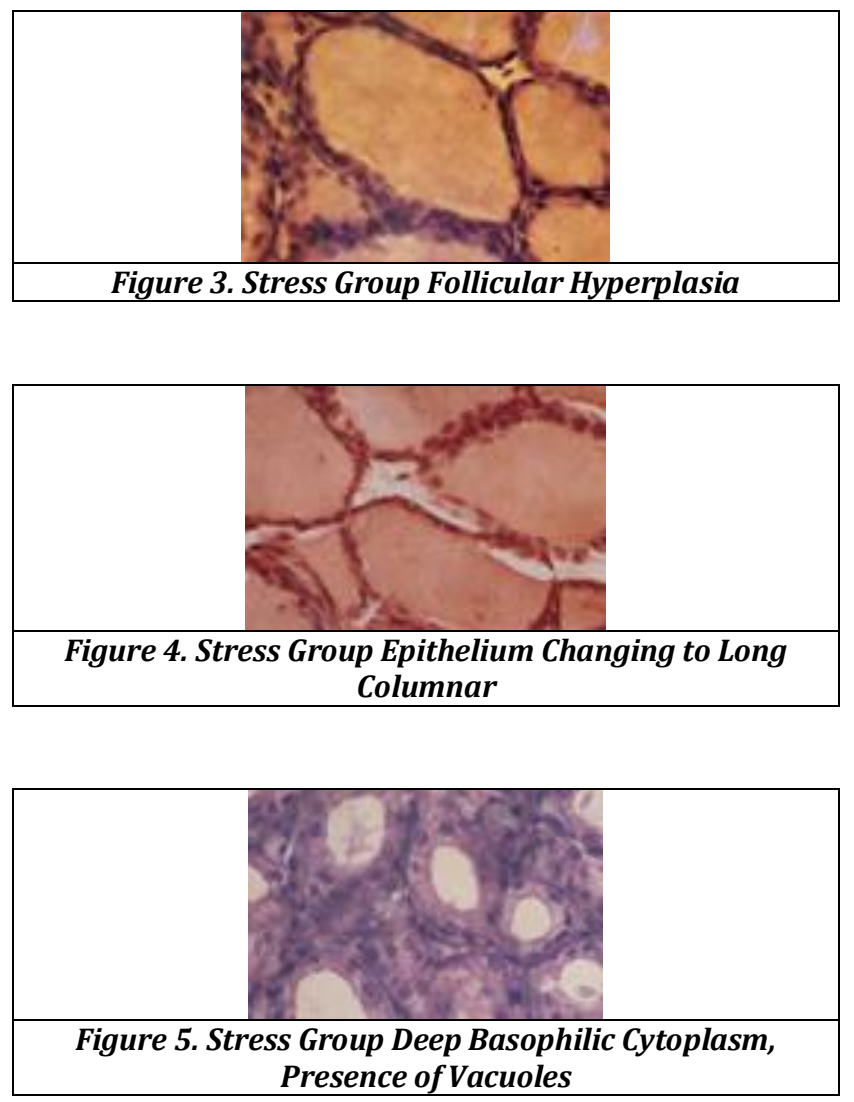

\section{DISCUSSION}

The present study showed that immobilisation stress/ restraint stress causes intense stimulatory effects on thyrofollicular activity.(9) The histological findings were in form of cellular hypertrophy and hyperplasia, follicular hyperplasia basophilic colloid and large pericolloidal spaces at the periphery. All these findings were seen maximum in group sacrificed on 7 th day.

These findings confirmed the features of. General Adaptation Syndrome as follicles showed almost no colloid material and high T4 level on 1st, 3rd, 7th day (Exhaustive Stress), small amount of basophilic colloid and low T4 level on 15th day and good amount of basophilic colloid filling the follicles along with. High T4 levels (Adaptive Stress). 


\section{CONCLUSION}

There is significant increase in the escape behavior and aggressiveness of stressed animals [10]. There were signs of thyroid hyperactivity in form of follicular hyperplasia and cellular hypertrophy in stress group. Epithelium of the follicular cells which was low cuboidal or flattened in control and diazepam group became high cuboidal to tall columnar with basal euchromatic nuclei in stress group. Cytoplasm of follicular cells became light basophilic to deep basophilic in stress group along with more number of granules and increased mitotic activity. Vacuoles were found in follicles at the periphery of colloid. They were more in females of stress group. Large pericolloidal spaces were found at the periphery of colloid in the group sacrificed at the end of 3 months. T4 levels were increased significantly on the $1^{\text {st }} 3^{\text {rd }}$ and $7^{\text {th }}$ day. Fall in T4 level was observed on 15th day. But its level was increased significantly $(\mathrm{P}<0.01)$ at the end of three months. Diazepam partially antagonized the effect of stress on all the parameters observed.

\section{REFERENCES}

[1] Canon WB. The influence of emotional states on the functions of alimentary canal. American Journal of Medical Sciences 1909;137:480-7.

[2] Mayfield D. Neuroendocrinology: a science for psychosomatic medicine. Psychosomatics 1980;21(12):971-3.

[3] Williams RB Jr. Neuroendocrine response and stress: behavioural mechanisms of disease. In: Williams RB Jr, edr. Perspectives on behavioural medicine: neuro endocrine control and behaviour. Vol. 2. Orlando FL: Academic Press 1985: p. 71-101.
[4] Koob GF. Stress corticotropin releasing factor and behavior. In: Williams RB Jr, edr. Perspective and behavioral medicine: neuroendocrine control and behaviour. Vol. 2. Orlando FL: Academic Press 1985: p. 38-52.

[5] Plakhuta-Plakutina GI, Kabitskil EN, Omstrieva NP, et al. Studies of the morphology of thyroid gland and thyroid hormones levels in the blood of rats in experiments on: "KOSMOS 1667" and "KOSMOS-1887". Kosm Biol Aviakosm Med 1990;24(4):25-7.

[6] Polozhentsev DS. Dynamics of thyroid function parameters during adaptation of body to prolonged psycho-emotional and physical stress. Fiziol Cheloveka 1992;18(2):155-7.

[7] Krasnoerov RA, Glumova VA, Trusov VV, et al. Thyroid morphofunctional changes in various types of experimental chronic stress. Probl Endokrinol (Mosk) 1992;38(3):38-41.

[8] Khoch HS, Lopukhova VV, Gratisianova AD. Change in the morpho-functional state of the thyroid gland during combined action of hypokinesis and cold. Bieul Eksp Biol Med 1994;118 (11):523-8.

[9] Dmitrieva NI, Idrisova DA, Vaido AI, et al. Morphofunctional parameters of the thyroid gland in late periods after prolonged stress in rat strains selected for nervous system, excitability. Probl Endokrinol (MOSK) 1994;40(1):50-2.

[10] Cizza G, Brady LS, Esclapes ME, et al. Age and gender influence basal and stress modulated hypothalamicpituitary-thyroidal function in Fischer 344/N Rats. Neuroendocrinology 1996;64(6):440-8. 